$w 34 \mathrm{~m}$

M. 71.5

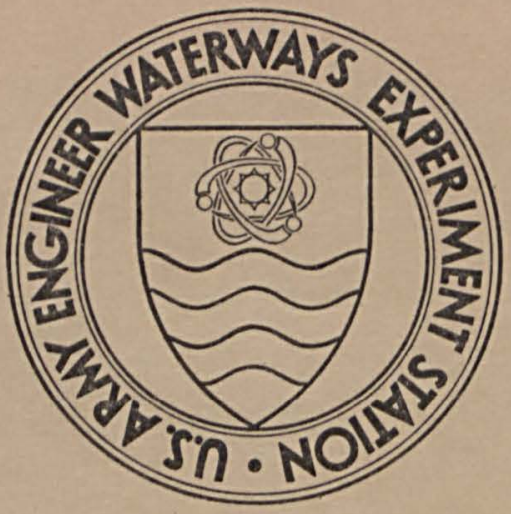

MISCELLANEOUS PAPER $M-71-5$

\title{
UTILIZATION OF SYNTHETIC SOILS IN ENGINEERING RESEARCH
}

by

A. J. Green
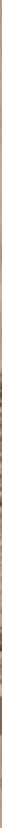

June 1971

Sponsored by Assistant Secretary of the Army (RED), Department of the Army

Conducted by U. S. Army Engineer Waterways Experiment Station, Vicksburg, Mississippi 


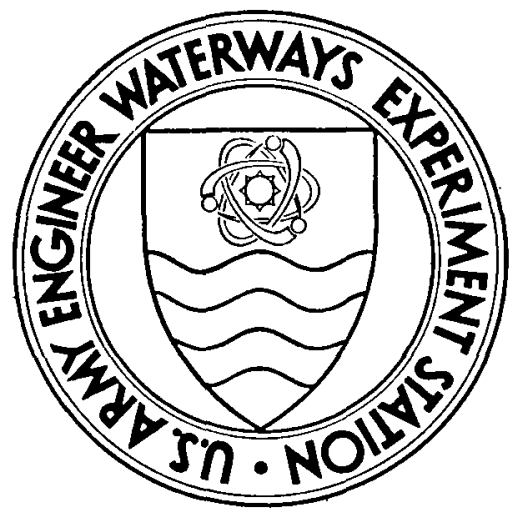

MISCELLANEOUS PAPER $M-7 I-5$

\section{UTILIZATION OF SYNTHETIC SOILS IN ENGINEERING RESEARCH}

by

A. J. Green

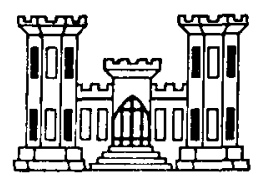

June 1971

Sponsored by Assistant Secretary of the Army (R\&D), Department of the Army Project 4A061101A9ID

Conducted by U. S. Army Engineer Waterways Experiment Station, Vicksburg, Mississippi 


\section{Foreword}

The study reported herein was conducted during the period 1969-1970 and was funded by Project 4A061101A91D, "In-House Laboratory Independent Research, Use of Synthetic Soils in Engineering Research - A Feasibility Study," sponsored by the Assistant. Secretary of the Army (R\&D).

The project was directed by Mr. A. J. Green, Research Projects Group, Mobility Research Branch (MRB), Mobility and Environmental (M\&E) Division, at the U. S. Army Engineer Waterways Experiment Station (WES). The test program was carried out by personnel of the MRB under the general supervision of Mr. W. G. Shockley, Chief, M\&E Division, and.Mr. S. J. Knight, Assistant Chief, M\&E Division, and Chief, MRB. The report was prepared by Mr. Green.

COL Levi A. Brown, CE, and COL Ernest D. Peixotto, CE, were Directors of WES during this study. Mr. F. R. Brown was Technical Director. 


\section{Contents}

Foreword. . . . . . . . . . . . . . . . . . . . .

Page

Conversion Factors, British to Metric Units of Measurement. . . .

Introduction. . . . . . . . . . . . . . . . . . . . . .

Background. . . . . . . . . . . . . . . . . . . .

Purpose and scope ......................

Synthetic Soils . . . . . . . . . . . . . . . . . . . 2

Users . . . . . . . . . . . . . . . . . . . 2

Categories. . . . . . . . . . . . . . . . 3

Several synthetic soils and their uses. . . . . . . . . 3

Advantages sought .................... . . . . . 4

Preparation and Maintenance of Test Soils . . . . . . . . . . . 4

Natural soils . . . . . . . . . . . . . . . 4

Synthetic soils . . . . . . . . . . . . . . . . 5

Comparative Tests of Natural and Synthetic Soils. . . . . . . . . 6

Tests by Selig and Rowe . . . . . . . . . . . . 6

Tests at WES. . . . . . . . . . . ...... 6

Disadvantages of Synthetic Soils. . . . . . . . . . . . . 8

Ongoing Research. . . . . . . . . . . . . . . . . . . . . . 9

Conclusions and Recommendations . . . . . . . . . . . . . 10

Conclusions . . . . . . . . . . . . . . . . . 10

Recommendations . . . . . . . . . . . . . . . 10

Selected Bibliography . • . • . . . . . . . . . . . . . Il

Personal Correspondence . . . . . . . . . . . . . . . . 11 Figures $1-4$ 
Conversion Factors, British to Metric Units of Measurement

British units of measurement used in this report can be converted to metric units as follows:

Multiply

inches

inches per minute

pounds per square inch

Fahrenheit degrees
By

2.54

2.54

6.8948

$5 / 9$
To Obtain

centimeters

centimeters per minute

kilonewtons per square meter

Celsius or Kelvin degrees*

* To obtain Celsius (C) temperature readings from Fahrenheit (F) readings, use the following formula: $C=(5 / 9)(F-32)$. To obtain Kelvin (K) readings, use: $K=(5 / 9)(F-32)+273.15$. 


\section{Summary}

This report summarizes published results and personal comments of a number of researchers who have used synthetic soil mixtures. It also contains a small amount of data collected at the Waterways Experiment station. In general, it can be said that whereas synthetic soils may be useful in some limited sense, they do not offer the panacea that earlier researchers claimed or hoped for. The engineering properties of many synthetic mixes may be more dependent on temperature and rate of loading than those of soil-water mixes. It is concluded that the usefulness of synthetic soils in engineering research is rather limited, and it is recommended that any researcher thoroughly study the behavioral patterns peculiar to a particular synthetic mix he may plan to use lest the utility of the information produced be restricted by them. 


\section{UTILIZATION OF SYNTHETIC SOILS IN ENGINEERING RESEARCH}

\section{Introduction}

\section{Background}

1. Engineering research studies that involve the use of soil can be very costly, and a large portion of the cost is attributable to the soil preparation. Inability to maintain stable conditions during the testing cycle plagues research programs involving natural soils both in the laboratory and in the field. This instability may be caused by a variety of factors, including moisture evaporation and thixotropic changes.

2. In the past, several researchers have attempted to use "synthetic soils," particularly in model studies; and whereas some seem quite pleased with their results, as many others are thoroughly displeased. However, a comprehensive comparison has not been made of the properties of natural and synthetic soils sufficient in scope to permit a prospective researcher to truly and objectively judge the relative merit of using synthetic soils.

3. There appear to be a number of possible advantages in using such materials. One possibility is the establishment of a standard reference material for a broad group of research programs being conducted in laboratories throughout the country. Also, such materials may have long-term stability, reproducibility of test conditions may be enhanced, and economic advantages may result in some instances. These possibilities alone seem to justify a comprehensive study of the properties of synthetic materials, and a comparison of their properties with those of natural soils.

4. There are a number of direct potential uses for synthetic soils in the defense-related research programs being conducted at the U. S. Army Engineer Waterways Experiment Station (WES). Among these are:

a. The development of design criteria and performance prediction methods for structures intended to provide protection against nuclear weapons.

b. The development of methodology for predicting and evaluating the performance of off-road vehicles and of aircraft landing gear assemblies designed for operation on unsurfaced landing strips. 
c. The development of technology for designing and predicting the operational life of pavements (prefabricated, flexible, and rigid).

d. The examination of the effects of explosive charges as a means of rapid earth excavation.

5. Unfortunately, sufficient funds for a comprehensive study are not available. Nevertheless, because WES personnel, in their association with engineers and scientists in many fields of research, have frequently been questioned regarding their opinion and/or that of the WES on the use of synthetic soils for various types of projects, this limited study was undertaken. This report contains the data available at the WES and comments of others currently active in the use of synthetic soils. Purpose and scope

6. The purposes of this study were to:

a. Review and record some of the uses of synthetic soils in the past decade.

b. Evaluate the advantages and disadvantages of using synthetic soils in lieu of soil-water mixtures.

These evaluations were based on considerations of preparation and maintenance, the relative magnitude of certain engineering properties, and longterm stabilities of the mixtures.

7. This program was limited to a literature review, communication with certain researchers experienced in the use of synthetic soils, and a limited amount of laboratory testing at the WES. The scope of this testing was limited to two clays mixed with several different pore fluids. The tests included evaluation of shear strength and of the effects of temperature and rate of penetration on penetration resistance.

\section{Synthetic Soils}

\section{Users}

8. To list all of the governmental organizations, industries, and universities that have used, are using, or tentatively plan to use synthetic soils is impractical; and to solicit comments from more than a selected few of the many possible users is equally impractical. Over the past 
few years, the following agencies have been contacted: U. S. Army TankAutomotive Command, National Aeronautics and Space Administration, U. S. Department of Agriculture, U. S. Department of the Navy, Caterpillar Tractor Company, John Deere Company, Illinois Technology Research Institute, State University of New York, and Stevens Institute of Technology.

\section{Categories}

9. Synthetic soils fall into several different categories. These are:

a. Entirely synthetic. For example, the use of gelatin to represent a cohesive material; glass beads or rods to simulate a purely frictional material; mixtures of beads and oil to simulate soil with both strength components, etc.

b. Synthetic pore fluids and/or binders. The combining of a single type of soil with a synthetic pore fluid or combination of pore fluids or with synthetic binding material, e.g. clay and glycol, sand and oil, asphalt and sand, etc.

c. Synthetic admixtures. Any mixture of two or more natural soils with artificial pore fluids, binders, or other nonsoil substances.

\section{Several synthetic soils and their uses}

10. Gelatin has been used to study stress patterns created by loading cohesive materials with model structure foundations and wheels. Glass beads and smooth rods have been used to represent frictional materials for the study of displacements generated by surface loading and by running wheels.

11. Natural soils with synthetic pore fluids (binders), as well as synthetic admixtures, have been used in studies of earthmoving equipment (scale models), effects of explosive charges, transient loading, tillage tools, vehicle mobility, etc.

12. Two common synthetic admixtures are clay-sand-oil and claysand-ethylene glycol with various percentages of the three constituents. Glycerin has also been used as a pore fluid in such mixes. These admixtures have been used in a variety of applications covering generally the same areas as listed in paragraph 10 above.

13. One researcher reported that he had produced a satisfactory synthetic soil for his needs by mixing kaolinite with two liquids from the 
family of plasticizers, dibutyl phthalate and dibutyl sebicate. The mixture of fluids was assigned the name Hydrate 121.

\section{Advantages sought}

14. The emphasis on the type of advantages sought may differ from one researcher to another, but there is a certain amount of commonality. A few of the advantages that have been mentioned are:

a. Long-term stability of the mix.

(1) Low evaporation rate

(2) No serious thixotropic changes

(3) No aggregation or disaggregation with time

(4) Repeatability of conditions

b. Establishment of standard (reference) materials for laboratories doing similar research throughout the country.

c. Economic gains. Although the initial cost of many synthetic soils or soil simulants may be high, there is the potential savings resulting from the lack of a need to remix certain materials with their pore fluids after long storage periods.

\section{Preparation and Maintenance of Test Soils}

\section{Natural soils}

15. The WES has had considerable experience in preparing and maintaining large volumes (up to several hundred cubic yards in a single test specimen) of soil-water mixtures in its mobility research programs. Two fine-grained soils (a heavy clay and a lean clay) and two coarse-grained soils (Yuma sand and crushed basalt rock) have been used. Classification and gradation data for these soils are shown in fig. 1.

16. Fine-grained soil-water mixtures. These mixtures are prepared by blending (in a pug mill) water with soil that has been previously dried and crushed into fine particles. The mixture is dumped from the pug mill into a soil bin (fig. 2), where it is compacted by a rubber-tired roller. About 95 percent saturation is achieved. In this state, this soil will remain stable for periods of a year or more, if the surface is kept covered with an impervious membrane and the material is infrequently (once or twice a week) sprayed lightly to compensate for moisture losses. This 
material can be reprocessed in place for many cycles without any noticeable change in behavioral properties, provided it is not allowed to dry. Spraying of the material is performed more frequently during the reprocessing and testing cycles.

17. Coarse-grained soil-water mixtures. During the past two years, the WES was faced with the problem of producing a soil test section of Yuma sand and one of crushed basalt (fig. 1), both of which had to possess cohesive and frictional strength components. The use of synthetic pore fluids was considered, since it was generally felt that water content levels greater than that present in the air-dry condition, i.e. about 0.5 percent, could not be maintained; however, this fear proved to be unfounded. Mixing was accomnlished by spreading the dry sand on a concrete floor, adding water, and blending the water with the soil by using hand tools, including a gasoline-engine garden rotary tiller. The mixture was then placed in a soil bin (fig. 2). By covering the soil when not in use and spraying the surface very lightly and frequently (30-minute intervals) during reprocessing and testing cycles, moisture content up to about 2 percent was easily maintained at a constant level. During idle or storage periods, the material was sprayed once or twice daily. Synthetic soils

18. Fine-grained. Difficulties were experienced at the WES in developing a homogeneous mixture (even distribution of pore fluids) of either the heavy clay or the lean clay with ethylene glycol or glycerin. When the synthetic soils were mixed by running them through a pug mill, as water is mixed with natural soil, they contained lumps of dry material, and increasing the mixing period did not solve this problem. A milling device had to be used, and only small batches of material could be prepared at one time. In some cases reported by others, artificial soils (clay-sandoil type) produced soil balls when they were reprocessed, and the balls grew in size and number with each reprocessing. To maintain such a mix might involve passing the material through a hammer mill, pug mill, or similar device. In other cases, the fluid separated from the soil solids (commonly called bleeding) when synthetic pore fluids were added in sufficient quantities to produce a purely cohesive material; cost of maintaining 
such a mix is high. As mentioned above in paragraph 13, success has been reported in mixing a fine-grained soil (kaolinite) with a mixture of two liquid chemical compounds that are members of a family of solvents or catalysts known as plasticizers. This material did not tend to "ball" or "bleed" and the maintenance requirements were less than those for other synthetic mixes.

19. Coarse-grained. No attempts have been made at the WES to produce coarse-grained synthetic soils. A review of the literature and discussions with researchers who have produced such soils indicate that no particular difficulties have been experienced in preparing and maintaining satisfactory coarse-grained synthetic soils.

\section{Comparative Tests of Natural and Synthetic Soils}

20. The following paragraphs are limited to a discussion of those tests conducted to evaluate the similarity of engineering properties of natural and synthetic soils. The discussion does not purport to assess the validity of certain types of tests in which synthetic soil was used, e.g. traction performance, forces on tillage tools, etc. Tests by Selig and Rowe

21. Selig and Rowe made a comparative evaluation of selected engineering properties of synthetic and natural soils. Results showed that Atterberg limits for a given soil differ with the pore fluids used for equivalent fluid contents. Further, the compaction curves (density versus fluid content) are different for the different pore fluids. Similarly, the relation of unconfined compressive strength of the compacted (equal compaction efforts) specimens to fluid content varies with the pore fluid used. These investigators concluded that the mixtures of clay and synthetic pore fluids lacked long-term stability.

\section{Tests at WES}

22. Testing of synthetic soils at the WES included an evaluation of:

a. The effect of rate of loading on penetration resistance.

b. The effect of temperature on penetration resistance. 
c. The effect of synthetic pore fluids on shear strength.

d. Long-term stability.

Where possible, results from the tests with synthetic soils were compared with those from tests with natural soils.

23. Effect of loading rate on penetration resistance. The effect of rate of loading on resistance to penetration of the WES cone penetrometer was examined for the two test clays (paragraph 15) mixed with two different pore fluids, glycerin and ethylene glycol, and the penetration resistance of the mixtures of clays and synthetic pore fluids was found to be more rate dependent than that of soil-water mixtures at or near room temperature (fig. 3). The penetration resistance of clay-glycerin mixtures had the highest dependence on the rate of loading. At a rate of penetration of $72 \mathrm{in./min,*}$ the penetration resistance of both the heavy clay and lean clay samples was about 67 percent higher than at $10 \mathrm{in.} / \mathrm{min}$, whereas the lean clay-glycol (stored 6 months) and heavy clay-glycol mixtures showed comparable increases of 25 and 34 percent, respectively. Also, for a given clay-fluid content-penetration speed combination, the penetration resistance was greater for the synthetic soils than for the natural soilwater mixtures.

24. Effect of temperature on penetration resistance. The penetration resistance of the synthetic soils was quite sensitive to changes in temperature, as shown in fig. 4, the clay-glycerin mixtures being the most sensitive for the conditions examined. The general trend was for the penetration resistance to increase as temperature decreased. The greatest change noted was in the lean clay-glycerin mixture; its penetration resistance increased by more than 200 percent when the temperature dropped from 140 to $46 \mathrm{~F}$.

25. Effect of synthetic pore fluid on shear strength. The Cohron sheargraph was used for in situ evaluations of the surface shear strength in both the natural and synthetic soils. In general, the synthetic soils tended to have greater strength than the clay-water mixtures. Shear

* A table of factors for converting British units of measurement to metric. units is presented on page vii. 
strength evaluation performed with the McRae gyratory machine yielded similar results. For example, when the Cohron sheargraph results at a normal pressure of $10 \mathrm{psi}^{*}$ were evaluated, the following results were obtained:

\begin{tabular}{|c|c|c|c|}
\hline Soil & Pore Fluid & $\begin{array}{c}\text { Fluid } \\
\text { Content } \\
\% \\
\end{array}$ & $\begin{array}{c}\text { Shear } \\
\text { Strength } \\
\text { psi }\end{array}$ \\
\hline Lean clay & Water & 28 & 7.5 \\
\hline Lean clay & Glycerin & 28 & 14.0 \\
\hline Heavy clay & Water & 37 & 4.0 \\
\hline Heavy clay & Glycerin & 37 & 10.0 \\
\hline Heavy clay & Ethylene glycol & 37 & 9.0 \\
\hline
\end{tabular}

The gyratory shear tests yielded the following:

\begin{tabular}{|c|c|c|c|c|}
\hline \multirow[b]{2}{*}{ Soil } & \multirow[b]{2}{*}{ Pore Fluid } & & \multicolumn{2}{|c|}{ Shear Strength, psi } \\
\hline & & $\begin{array}{c}\text { Fluid } \\
\text { Content } \\
\%\end{array}$ & $\begin{array}{c}\text { 50-psi } \\
\text { Normal } \\
\text { Pressure }\end{array}$ & $\begin{array}{c}100-p s i \\
\text { Normal } \\
\text { Pressure }\end{array}$ \\
\hline Heavy clay & Water & 37 & 5 & 5 \\
\hline Heavy clay & Glycerin & 37 & 17 & 22 \\
\hline Heavy clay & Ethylene glycol & 37 & 11 & 18 \\
\hline
\end{tabular}

26. Long-term stability. The brevity of the program and the low funding level did not permit a detailed evaluation of the changes in the engineering properties of the mixtures with time; however, a few observations were made. There was no apparent "bleeding" of the mixtures that were stored for periods up to 12 months. Some balling did occur; but since the soil was not subjected to extensive reprocessing, the magnitude of this problem could not be ascertained.

\section{Disadvantages of Synthetic Soils}

27. Synthetic soils that are prepared by mixing synthetic pore fluids or binders with one natural soil or an admixture of soils have a number of disadvantages, some of which are:

* The Cohron sheargraph is normally operated in a range of normal pressures from 0 to $15 \mathrm{psi}$, whereas the gyratory shear device, designed for higher pressures, was operated at normal pressures of $50 \mathrm{psi}$ and above. 
a. Difficulty in the mixing process to achieve a homogeneous mixture, thereby resulting in high initial processing costs.

b. High cost of synthetic pore fluids and binders.

c. Bleeding of "wet" mixes that are intended to represent cohesive soil, i.e. pore fluids separate from the mix if it is left standing, and continuous maintenance of the $\mathrm{mix}$ is required.

d. Forming of soil balls in "dry" mixes, such as those used to represent friable soils in agricultural equipment research laboratories, when the mixes are reprocessed, so that after several processing cycles, the material must be removed from the testing line, the balls broken up, and the material completely remixed.

e. Greater dependency on temperature changes and rate of loading of the penetration resistance of synthetic soils (clay mixed with ethylene glycol or with glycerin) than that of clay-water mixtures.

28. The above comments apply, in the main, to mixes with pore fluids that are more viscous than water and with viscosities more temperature dependent than that of water.

\section{Ongaing Research}

29. According to a recent report by the State University of New York at Buffalo, a synthetic mix that lacks some of the disadvantages mentioned in the preceding paragraphs is being prepared and used in its facilities (paragraphs 13 and 18). The $\operatorname{mix}$ is a combination of kaolinite and Hydrate 121 (a mixture of dibutyl phthalate and dibutyl sebicate). These liquids are mixed in proportions necessary to form a liquid whose specific gravity is one (equivalent to that of water). This synthetic mix presented no serious initial mixing problem, has been stable for almost a year, and shows no signs of deterioration due to reprocessing; however, it has not been evaluated with respect to rate of loading and temperature effects.

30. The researchers have postulated that mixing and stability problems are less severe for Hydrate 12l-kaolinite mix than for other synthetic mixes because the molecule diameters of the two constituent liquids of Hydrate 121 approach that of water. Further, the penetration resistance 
of this synthetic mix may not be as sensitive to changes in rate of loading and temperature as other synthetic mixes because the pore fluid, Hydrate 121, has a viscosity similar to that of water, and its viscosity is less sensitive to temperature changes than that of other fluids commonly used in synthetic soils.

31. Without a doubt, better synthetic mixes can be had than those commonly used in the past, but each new $\operatorname{mix}$ needs to be carefully evaluated. In the opinion of this author, the evaluation requirements are extensive enough in many cases to force a conclusion that the use of natural soils is more economically feasible than the use of synthetic ones.

\section{Conclusions and Recommendations}

\section{Conclusions}

32. Based on the information that has been compiled from other researchers and the limited amount of data available, the following tentative conclusions were reached:

a. Synthetic soils do not offer the panacea that earlier researchers claimed or hoped for.

b. Many mixes lack long-term stability, and thus do not offer economic advantages and cannot be used as standard reference soils.

c. The penetration resistance of synthetic mixes is very likely to be more dependent on temperature and rate of loading than that of soil-water mixes.

d. The problems listed in conclusions $\underline{b}$ and $\underline{c}$ restrict the usefulness of synthetic soils in development of systems for predicting the behavior of prototype soil-structure (or any soil-foreign object) interaction systems in their natural environment, based on laboratory (model or prototype) testing.

e. With a little extra effort, natural soils can be maintained in a stable condition for relatively long periods of time.

\section{Recommendations}

33. Any researcher or consultant, prior to selecting or recommending a synthetic soil, should make certain that he fully understands the 
behavioral patterns peculiar to that $\mathrm{mix}$ so that the utility of the information produced is not restricted by them.

34. Strong consideration should be given to the trade off between exercising greater-than-normal care in preparing and maintaining natural mixes, i.e. soil-water, and the high initial cost and other problems connected with synthetic soils before any research program involving soils is undertaken.

\section{Selected Bibliography}

Clark, S. J. and Liljedahl, J. B., "Soil Bins, Artificial Soils and Scale Model Testing," Transactions of the American Society of Agricultural Engineers, Vol 11, No. 1, 1968, pp 198-202.

Hanamoto, B., "Artificial Soils for Laboratory Studies in Land Locomotion," Report No. 20, Nov 1957, Land Locomotion Laboratory, U. S. Army TankAutomotive Center, Warren, Mich.

Korayem, A. Y. and Reeves, C. A., "Artificial Soils Simulate Natural Soils in Tillage Studies; Parts I and II," Transactions of the American Society of Agricultural Engineers, Vol 9, No. 2, 1966, pp 145-150.

Selig, E. T. and Rowe, R. D., "A Study of Artificial Soils," Preprint No. 95, Oct 1960, American Society for Testing Materials, Philadelphia, Pa. Turnage, G. W., "Measuring Soil Properties in Vehicle Mobility Research; Effects of Velocity, Size, and Shape of Probes on Penetration Resistance 0: Fine-Grained Soils," Technical Report No. 3-652, Report 3, Nov 1970, U. S. Army Engineer Waterways Experiment Station, CE, Vicksburg, Miss.

Wang, C.-T., "Moisture Content Determination for Redsod Artificial Soils," (unpublished contract report), June 1970, State University of New York, Buffalo, N. Y.

\section{Personal Correspondence}

Ehrlich, I. R., Personal Correspondence, Stevens Institute of Technology, Hoboken, N. J., 1970-71.

Selig, E. T., Personal Correspondence, State University of New York, Buffalo, N. Y., 1970-71.

Wismer, R. D., Personal Correspondence, Deere and Co. Technical Center, Moline, Ill., 1970-71. 


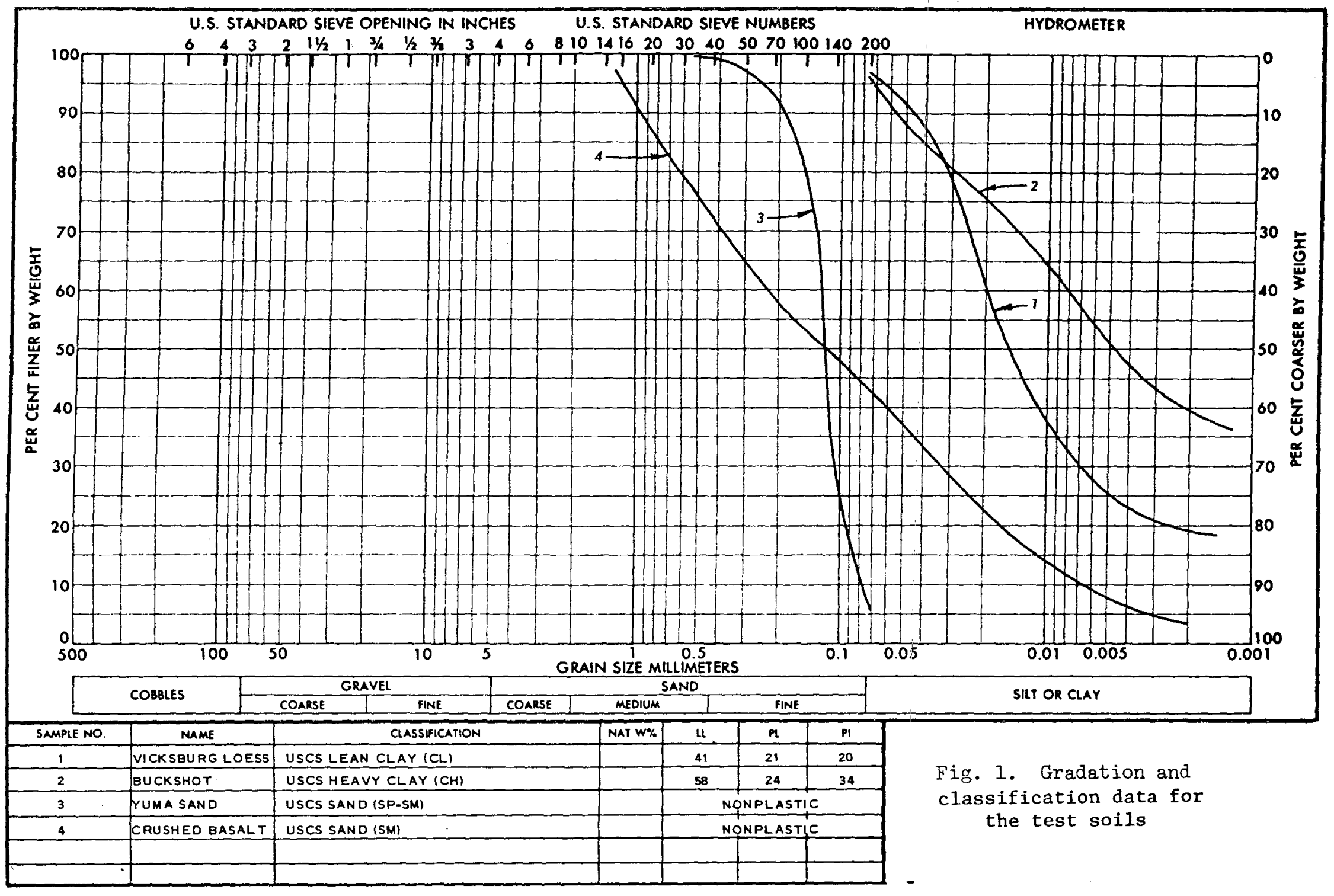




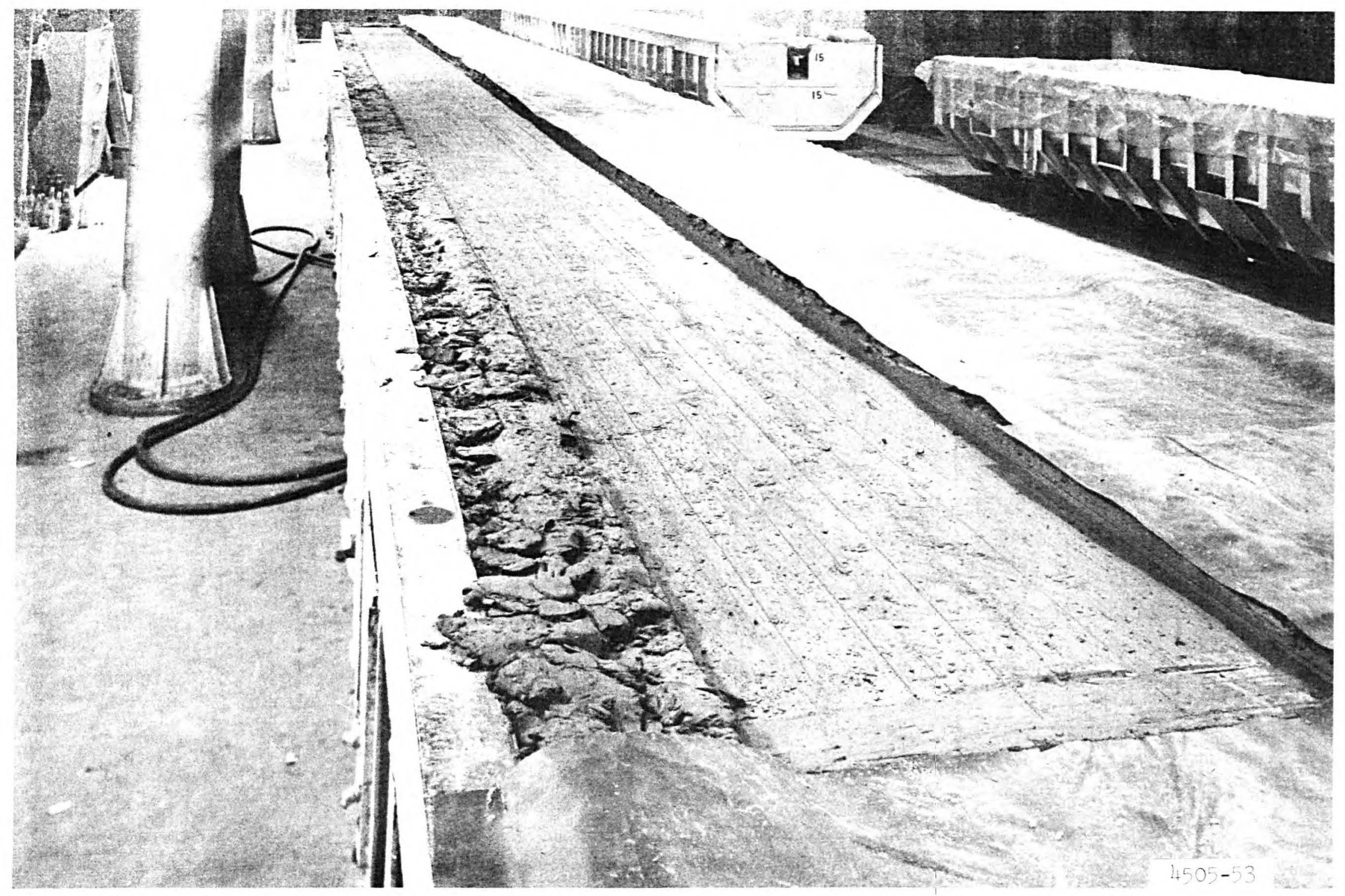

Fig. 2. Soil test bin with right side covered to prevent moisture loss. Note bin in right background completely covered 


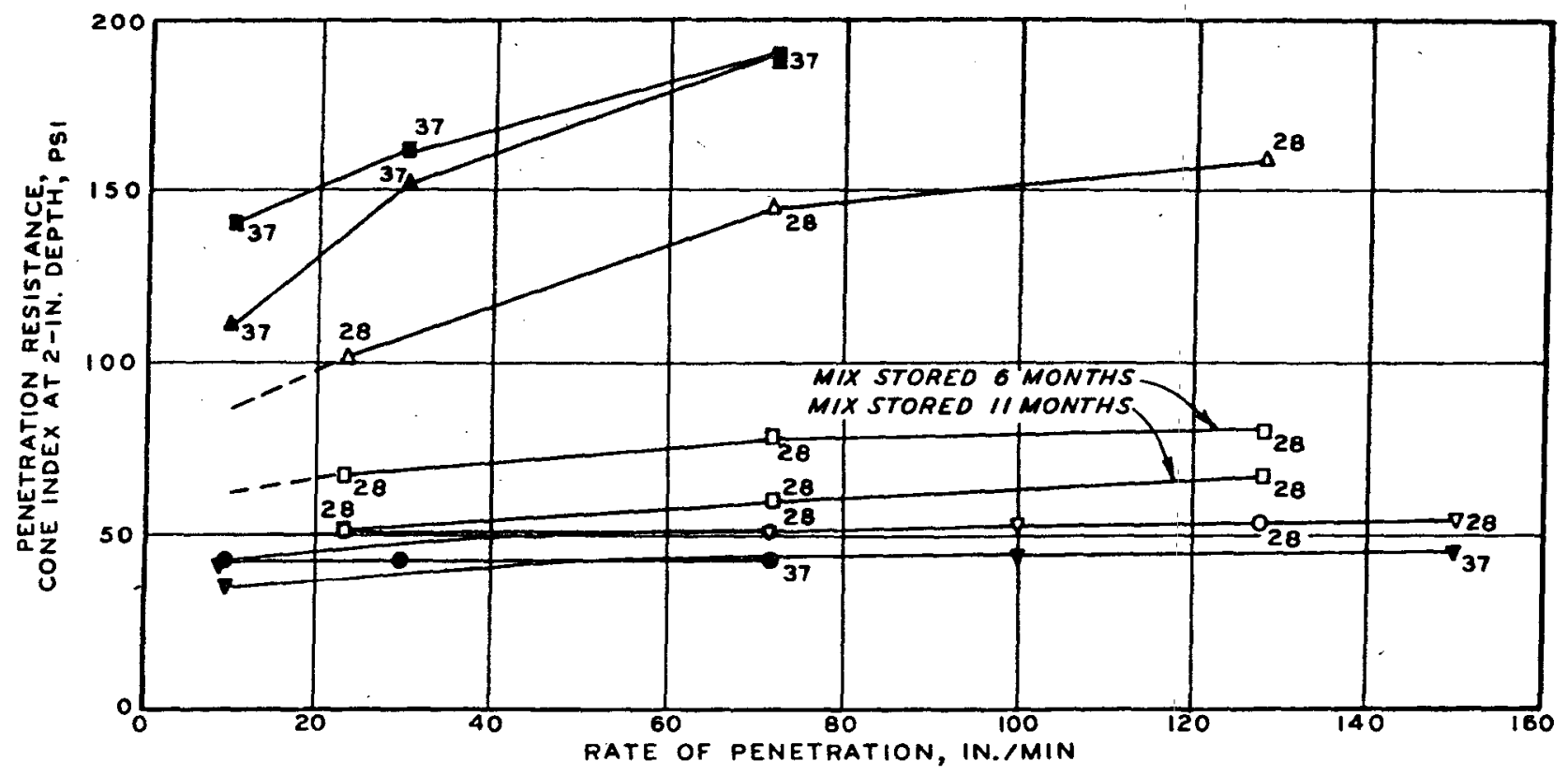

\section{LEGEND}

- heAvy Clay AND water

LEAN CLAY AND WATER

HEAVY ClaY AND WATER *

- LEAN CLAY AND WATER *

- heavy clay and glycerin

- Lean clay AND gLYCERIN

- heavy clar and glycol

- HEANY CLAAY AND GLYCOL

NOTE: NUMERALS ON PLOT DENOTE

FLUID CONTENT IN PERCENT.

* COMPUTEd RESULTS From tURNAGE.

Fig. 3. Penetration resistance versus rate of penetration; temperature $=72-78 \mathrm{~F}$ 


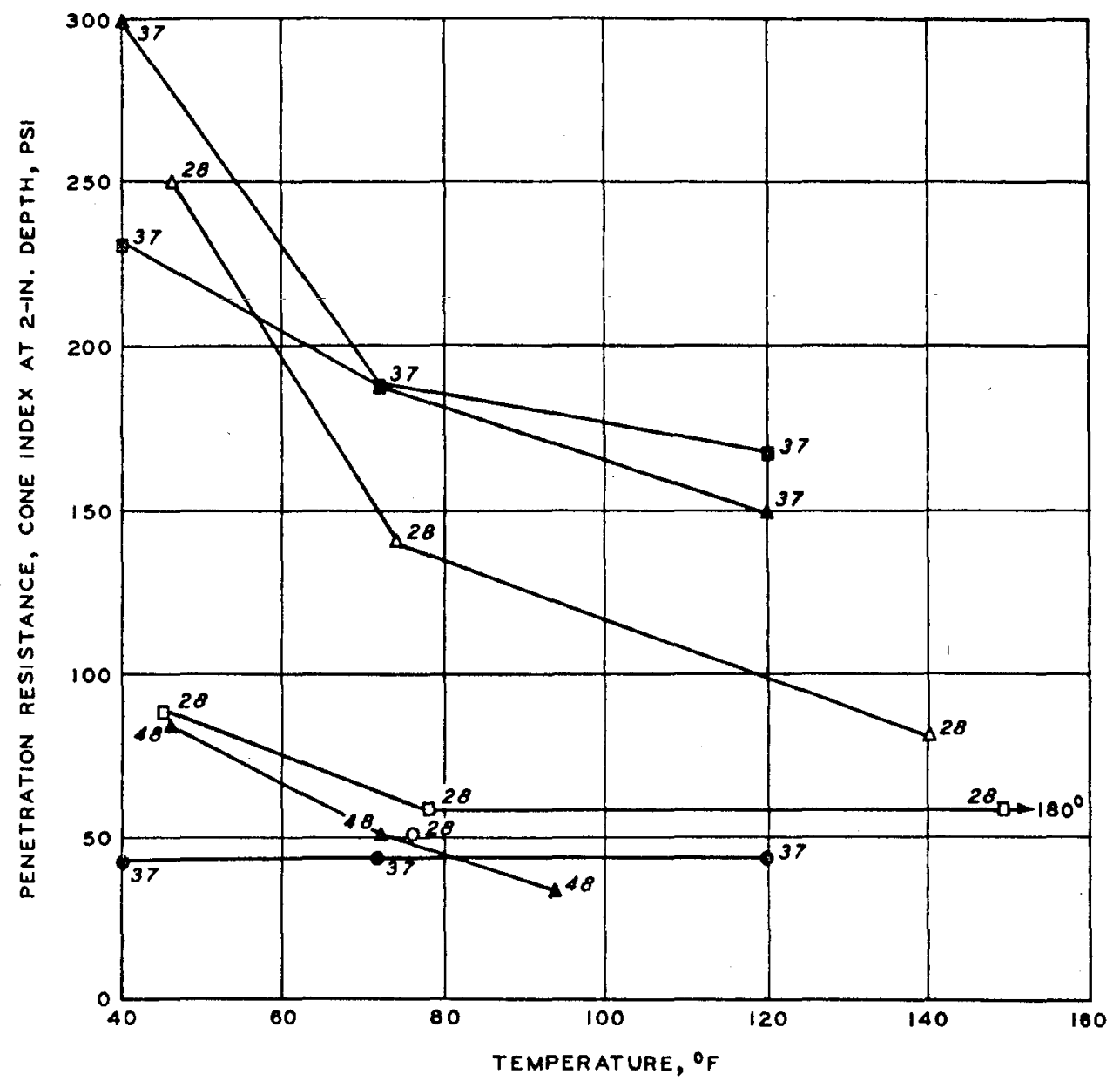

\section{LEGEND}

- heavy clay and water

- lean clay and water

$\triangle$ HEAVY CLAY AND GLYCERIN

$\triangle$ LEAN CLAY AND GLYCERIN

* HEAVY CLAY AND GLYCOI.

- LEAN CLAY AND GLYCOL

NOTE: NUMERALS ON PLOT DENOTE

FLUID CONTENT IN PERCENT.

Fig. 4. Penetration resistance versus temperature; velocity $=72 \mathrm{in} . / \mathrm{min}$ 
Unclassified

Security Clessification

DOCUMENT CONTROL DATA - R \& D

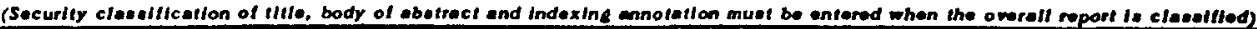
1. ORIGINATING ACTIVITY (Comorafo author) Pa. REPOAT SECURITY CLASBIFICATION

U. S. Army Engineer Waterways Experiment Station

Vicksburg, Mississippi

Unclassified

3. REPOAT TITLE

UTILIZATION OF SYNTHETIC SOILS IN ENGINEERING RESEARCH

4. DESCRIP TIVE NOTES (TVpo of report and inclualve datea)

Final report

5. AU THOA(S) (Flrat name, middlo InIllel, laet nomo)

Andrew J. Green

\begin{tabular}{|c|c|c|}
\hline D. REPOAT DATE & 7\%. TOTAL NO. OFPAGES & 76. NO. OF AKFE \\
\hline June 1971 & 20 & 6 \\
\hline 6. CONTAACT OR GRANT NO. & \multicolumn{2}{|c|}{ Da. ORIGINATOR'S REPORT NUAPERR(S) } \\
\hline 4A061101A91D & \multicolumn{2}{|c|}{ Miscellaneous Paper $\mathrm{M}-71-5$} \\
\hline c. & \multicolumn{2}{|c|}{ 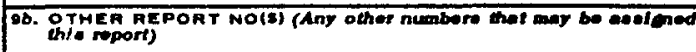 } \\
\hline d. & & \\
\hline
\end{tabular}

10. DISTAIDUTION STATEMENT

Approved for public release; distribution unlimited

\begin{tabular}{|l|l|}
\hline 11. SUPDLEMENTARY NOTES & $\begin{array}{l}\text { 12. SPONSORING MILITARY ACTIVITY } \\
\text { Assistant Secretary of the Army (R\&D), } \\
\text { Department of the Army, Washington, D. C. }\end{array}$
\end{tabular}

18. AGSTAACT

This report summarizes published results and personal comments of a number of researchers who have used synthetic soil mixtures. It also contains a small amount of date collected at the Waterways Experiment Station. In general, it can be said that whereas synthetic soils may be useful in some limited sense, they do not offer the panacea that earlier researchers claimed or hoped for. The engineering properties of many synthetic mixes may be more dependent on temperature and rate of loading than those of soil-water mixes. It is concluded that the usefulness of synthetic soils in engineering research is rather limited, and it is recommended that any researcher thoroughly study the behavioral patterns peculiar to a particular synthetic mix he may plan to use lest the utility of the information produced be restricted by them. 
Unclassifled

security Clasellication

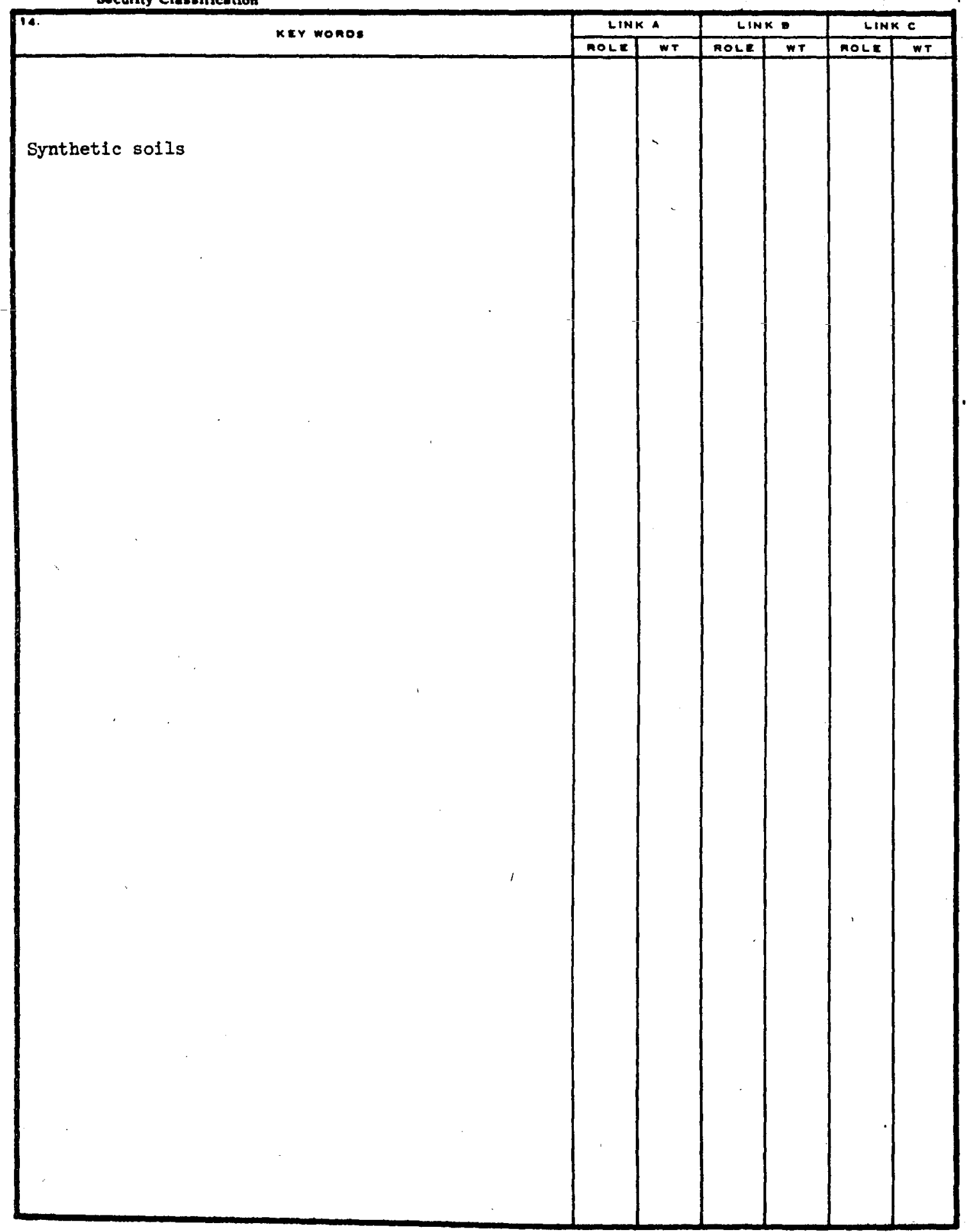

Unclassified 